DOI 10.15393/j9.art.2019.5701

УДК 821.161.1.09

Иван Сергеевич Леонов

(Москва, Российская Федерация)

mamif.lis@rambler.ru

\title{
Жанр проповеди в поэтике книги архимандрита Тихона (Шевкунова) «"Несвятые святые” и другие рассказы»
}

Аннотация. Статья посвящена особенностям жанра проповеди в книге архимандрита Тихона (Шевкунова) “Несвятые святые” и другие рассказы». Предметом исследования являются проповеди как самого повествователя, так и фрагменты проповедей авторитетных священнослужителей XX-XXI веков. Они сочетают традиционные черты и жанровые новации: параллельное обращение к священному тексту и событиям современности, детализацию, создание психологических характеристик, эмоциональную напряженность, соединение тринитарной формулы и авторской оценки. Отмечено, что в ряде глав автор произвел замену текста проповеди на масштабное нравственно-назидательное приложение, развернутое изображение эпизодов повседневной жизни, перенес события из сакрального в бытовой локус. В ходе анализа «молчаливой проповеди» выявляется редукция ее основных жанровых элементов, отсутствие прямого обращения к священному тексту, повышенное внимание к личности проповедника и сущности его миссионерского призвания. Таким образом, все повествование рассматривается как целостная проповедь о встрече человека со своим Создателем.

Ключевые слова: православная словесность, литература, архимандрит Тихон (Шевкунов), “Несвятые святые” и другие рассказы», проповедь, Священное Писание, жанр

$\mathrm{K}$

нига архимандрита (в настоящее время - митрополита) Тихона (Шевкунова) «"Несвятые святые” и другие рассказы», вышедшая из печати в 2011 г., вызвала значительный интерес у читателей и исследователей-литературоведов. Один из дискуссионных вопросов связан с выявлением жанровой природы произведения, которая представляется неоднородной. О. Н. Скляров отмечает, что в «Несвятых святых» сочетаются элементы мемуарно-биографического повествования, романа воспитания, церковно-исторической хроники, жизнеописания, притчи, легенды и т. д. [Скляров]. Н. В. Пращерук рассматривает произведение

(С) И. С. Леонов, 2019 
с точки зрения влияния на него древних «учительных книг», чья традиция отражена «золотой россыпью мудрых мыслей и замечательных афоризмов, которые принадлежат как героям, так и самому повествователю» [Пращерук: 24]. По мнению Д. М. Рогозина, книга «Несвятые святые» принадлежит к редкому для православной литературы, но популярному в среде светских авторов жанру - «бытописанию православного монастыря и жизнеописанию российского священства, представленному в биографическом повествовании» [Рогозин: 171].

В научной литературе вопрос о принадлежности данного произведения к жанру проповеди поставлен Е. А. Федоровой (науч. рук.) и Л. Н. Голубевой [Голубева: 125], однако он требует дальнейшего изучения. В широком смысле все произведение при его жанровом и стилевом многообразии представляет собой развернутую проповедь, посвященную поиску пути к обретению духовного спасения и встрече человека с Творцом. Замысел «Несвятых святых» раскрывается в следующих размышлениях автора:

«Один подвижник как-то сказал, что всякий православный христианин может поведать свое Евангелие, свою Радостную Весть о встрече с Богом. Конечно, никто не сравнивает такие свидетельства с книгами апостолов, своими глазами видевших Сына Божия, жившего на земле. И все же мы, хоть и немощные, грешные, но Его ученики, и нет на свете ничего более прекрасного, чем созерцание поразительных действий Промысла Спасителя о нашем мире».

При анализе проповеди как жанра в ракурс нашего исследования попадают как проповеди самого повествователя, так и фрагменты проповедей иных персонажей книги, являющихся обладателями священного сана. Возникает потребность рассмотреть их функции и способы воплощения.

Следует уточнить, что под проповедью понимается «поучение, речь, духовное слово, наставление священника пастве, в церкви, либо народно, в ином месте»². Кроме того, важными жанрообразующими признаками проповеди являются нравственные выводы и наличие традиционной тринитарной формулы: «Во имя Отца и Сына и Святаго Духа! Аминь». 
Структура проповеди включает вступление, изложение основной темы и нравственное приложение, которое должно стимулировать слушателей к формулировке выводов, а также заключение.

На сегодняшний день жанр проповеди достаточно хорошо изучен с точки зрения лингвистики [Агеева], [Белкина], [Нестеров], [Звездин], [Истомина], [Ицкович, 2006, 2007], [Крылова], [Бурцев], методики преподавания филологических дисциплин [Шубина]. Отдельные исследования посвящены стилистическим особенностям проповедей ведущих представителей церковного красноречия [Сибирева], а также содержат практическое руководство по подготовке текстов данного жанра [Брага]. Особого внимания заслуживают работы, посвященные проповеди как жанру церковной словесности, ее генезису, риторике и поэтике [Амвросий], [Антоний], [Гроссу], [Волкова].

Становление и эволюция проповеди - предмет изучения архиепископа Антония (Вадковского), который исследовал три периода развития жанра: а) время апостолов и святителя Василия Великого; б) древнеболгарский период, связанный с личностью и служением епископа Константина; в) древнерусский этап. Обращение к генезису жанра позволило выявить зародившиеся в византийской традиции его особенности: появление драматического элемента, склонность к диалогичности, наличие развернутой сюжетной составляющей, включение в тексты внутренних размышлений (в отдельных случаях - сомнений, переживаний) участников библейских событий, появление их портретных характеристик (см.: [Волкова]). Специфике импровизированной проповеди и особенностям подготовки к ней посвящены работы архиепископа Антония (Ключарева) [Антоний] и В. В. Буреги [Бурега].

При анализе произведения арх. Тихона (Шевкунова) «Несвятые святые» с точки зрения наличия в нем элементов проповеди нами рассматриваются фрагменты из книг Священного Писания, используемые автором при описании богослужений и требующие толкования и донесения до слушающих особого нравственного вывода («священный текст»). Как правило, это не дословное цитирование Библии, а пересказ. Чтобы донести 
ценностную составляющую отрывков из Евангелия, проповедник дает характеристику основных качеств библейских персонажей, оценку их поступков, приводит примеры событий из окружающей действительности, хорошо знакомые прихожанам, многие из которых были их свидетелями или участниками.

Подобный подход соотносится с идеями Т. В. Ицкович, которая выделяет в проповеди предметно-сакральную и профанную темы: первая связана с событиями, отраженными в корпусе книг Священного Писания, реализация второй «происходит в тексте проповеди в тех случаях, когда автору необходимо обратить внимание слушателей на современную действительность» [Ицкович, 2007: 10].

Проповеди в произведении представлены в нескольких аспектах. В нем обнаруживается образец завершенной проповеди, занимающий всю главу «Проповедь в воскресенье 23-е по Пятидесятницу 6/19 ноября 1995 г.». Повествователь указывает точную дату ее произнесения, что вводит читателя в календарный и литургический контексты, обращает к прочтенному за богослужением евангельскому фрагменту об исцелении Христом неизлечимо больной женщины (Мк. 5:25-34).

В этой проповеди сочетаются как традиционные, так и собственно авторские признаки жанра. К традиционным можно отнести наличие формулы «Во имя Отца и Сына и Святаго Духа! Аминь». Структура проповеди содержит две неравные части, первая посвящена пересказу одного из библейских событий («священный текст»), а другая интерпретирует эпизод из недавнего прошлого, хорошо знакомый многим слушателям. При этом обращает на себя внимание явная асимметрия, при которой события настоящего времени анализируются более развернуто.

Евангельский текст и история из жизни монастыря объединены общей идеей: истинная вера способна творить чудеса. Пересказывая библейский сюжет, священник употребляет нестандартное для церковного поучения выражение, ставящее чудо Христа в особое, не имеющее прецедентов положение: «Произошло это исцеление как-то странно...» (271). Слова 
Спасителя: «Велика вера твоя! Иди с миром» (272) - и комментарий к ним проповедника, объяснявшего необходимость борьбы с ложным стыдом, представляют собой особый тезиспереход, указывающий на ценностно-смысловую связь между двумя частями проповеди.

Далее священнослужитель переходит к событиям недавнего прошлого, призывая собравшихся вспомнить встречу престольного праздника, в ходе которого в монастырь на время была перенесена почитаемая икона Владимирской Божией Матери. В проповеди имеются указания на праздничные локусы, отмечены масштабность события («В крестном ходе, начавшемся в Кремле и завершившемся здесь, в Сретенском монастыре, участвовали более тридцати тысяч человек» - 272) и временной контекст («Был уже третий час ночи...» - 273). Автор использует детали, призванные показать неординарность празднуемого события, особый духовный настрой верующих, их склонность к преодолению неудобств ради поклонения святыне:

«Лил сентябрьский дождь. Святейший Патриарх и сонм духовенства в насквозь мокрых облачениях медленно шли вслед за иконой, а люди стояли вдоль улиц и, когда великую святыню проносили мимо них, опускались на колени - в лужи, на мокрый асфальт - никто не глядел куда» (272).

Заявленный в данном фрагменте драматизм усиливается при описании поведения милицейского начальника, решившего побороть ложный стыд и прилюдно приложиться к чудотворному образу. Возникновению особого эмоционального накала здесь способствуют следующие художественные приемы: создание атмосферы ночного полупустого храма, использование мотива «последней возможности» («Вот сейчас единственный шанс в вашей жизни, когда в такой день и в таком месте вы можете подойти к великой иконе...» - 274), детализированное изображение психологического состояния генерала, решившегося приложиться к образу («с лицом, мгновенно покрасневшим, как советский флаг», «сердито крякнул», «неумело положил перед ней <иконой> три поклона», «громко чмокнул», «стал что-то усердно шептать» - 275). 
В проповеди возникает мотив исцеления, чуда, совершенного по вере просившего, объединяющий евангельское событие и эпизод из жизни современной автору Москвы («священный текст» и «событие»), тем самым подчеркивается их вневременной и внепространственный характер. Образы библейской женщины и сестры генерала представлены параллельно, за тем лишь исключением, что первая получает исцеление по собственной вере, а вторая - по вере своего брата, преодолевшего страх и свидетельствовавшего о ней перед своими сослуживцами и подчиненными.

В финале проповеди священник приводит слова апостола Павла, который «обнаружил важнейший, основополагающий закон нашего мира. И сформулировал его так: "Господь Иисус Христос вчера и сегодня и во веки - Тот же!”» (277). Этим раскрывается глубинный смысл как самого события, так и его надвременной характер.

В заключительной фразе проповеди присутствует только один элемент тринитарной формулы - «Аминь», - который является фрагментом реплики, выходящей за пределы жанрового канона и свидетельствующей об особом эмоциональном состоянии проповедника: «Что можно к этому добавить? Только одно, древнее и радостное: аминь!» (277).

Параллельное изображение событий, разделенных двухтысячелетним историческим периодом, детализация, создание психологических портретных характеристик, эмоциональная напряженность, сочетание этикетных формул и авторской оценки - все это является гармоничным соединением традиционных и новаторских признаков проповеди в тексте произведения «Несвятые святые».

Обратимся к главе «Слово на литургии на монашеском постриге в Сретенском монастыре». В ней представлена проповедь, в которую кратко включен «Священный текст», связанный с эпизодом благословения детей Спасителем. Основное внимание повествователя сосредоточено на только что совершенном монашеском постриге - событии, выходящем за рамки проповеди.

Связующим элементом между «священным текстом» и описываемым событием (постригом) является образ стоящего 
перед Спасителем ребенка, который символизирует новопостриженного монаха: «Всякий монах после пострижения перед Господом как ребенок, безгрешный, перед которым открывается новая жизнь» (429). Образ ребенка соотнесен повествователем с образом Игнатия Богоносца, в детстве, согласно Преданию, благословленного Христом и впоследствии «претерпевшего мученичество за Христа и оставшегося верным Ему» (429).

В этой главе переход от самой проповеди к событию, связанному с ее содержанием, но выходящему за ее границы, довольно резкий. За финальной частью тринитарной формулы «Аминь!» (при этом ее начало «Во имя Отца...» опущено) следует «post scriptum», в рамках которого предельно кратко и сдержанно говорится об уходе монаха из обители. Затем описаны горькие размышления наместника о судьбе отказавшегося от выполнения обетов монаха, которые касаются трагизма произошедшего, признания жестокости церковных канонов по отношению к «бывшим» инокам, выражают надежду на милосердие Божие («Конечно, Господь милостив, и для всех есть покаяние...» - 431). Священнослужитель, объясняя духовный смысл произошедшего в обители, проводит аналогию с реальной жизненной ситуацией, выраженной в поэтических строках:

«Я - сын монаха, плод греха.

Я - нарушение обета.

И Богом проклят я за это:

К чему ни прикоснусь - труха» (431).

Это личный опыт профессора философского факультета МГУ Арсения Чанышева, сына монаха, оставившего монастырь.

В ряде глав книги «Несвятые святые» происходит замена собственно текста проповеди: он вытесняется масштабным нравственно-назидательным приложением. Иначе говоря, основной акцент делается на описываемом событии (согласно терминологии Т. В. Ицкович - профанной теме), а «священный текст» остается на подсознательном уровне без упоминания конкретных эпизодов из Библии (речь идет об уверенности в мудрости Промысла Создателя, силе молитвы и т. д.). Наряду с этим меняется локус, уходит на второй план сакрально-литургическое пространство православного 
храма, в котором, согласно традиции, произносится проповедь.

Подобный пример можно обнаружить в главе «О том, как мы покупали комбайны». На первый взгляд, проповедь здесь не представлена. Повествователь излагает детективную историю о поиске бухгалтера-авантюриста, ограбившего монастырскую кассу и скрывшегося за границей. Глава состоит из цепочки эпизодов, которые могут быть восприняты как случайные совпадения. Однако, по мысли автора, они являются свидетельством Промысла Божьего и происходят чудесным образом по молитвам братии монастыря. Описанные события (наказание преступника и возвращение денег в обитель), произошедшие вопреки логике и законам юриспруденции, воспринимаются повествователем как живое присутствие Бога в повседневной жизни. Эта история формирует замысел и основное содержание будущей проповеди:

«На праздничной литургии мне не надо было думать о теме проповеди. Я поведал прихожанам случившуюся историю и торжественно показал всему храму привезенную утром коробку <с деньгами>» (539).

Сюжетом некоторых глав книги становятся жизнеописания выдающихся монахов, чаще всего являющихся насельниками Псково-Печерского монастыря. Автор приводит отдельные реплики или фрагменты проповедей архимандрита Алипия (Воронова), отца Иоанна (Крестьянкина) и других священнослужителей. Обращение к конкретным эпизодам, кратким сюжетам, поучительным мыслям старцев тесно связано с определенной духовной доминантой каждого из них. В этом смысле проповедь становится формой биографического повествования.

Так, при описании биографии отца Алипия (Воронова), наместника монастыря, он предстает в образе «духовного монахавоина». При этом автор наряду с иноческим именем священника использует его мирское имя - Иван, рассказывая о фронтовом прошлом героя. Убедительно звучат слова архимандрита, воспринимающего свое служение в церкви как продолжение военного подвига: «Побеждает тот, кто переходит в наступление» (193). 
В проповедях отца Алипия возникают мотивы любви и веры как главного оружия, характеризующего его как духовного воина:

«Смотрите на мир только сквозь призму любви, и все ваши проблемы уйдут: внутри себя вы увидите Царствие Божие, в человеке - икону, в земной красоте - тень райской жизни. Вы возразите, что любить врагов невозможно. Вспомните, что Иисус Христос сказал нам: "Все, что сделали вы людям, то сделали Мне”» (205).

В этой главе наблюдается четкое выделение «священного текста», на первый взгляд, недостаточно соотносящегося с событийной стороной повествования. Однако если воспринимать данный фрагмент проповеди как неотъемлемую часть повествования о жизни «Великого наместника» и о судьбе возглавляемого им монастыря в определенную историческую эпоху, о ежедневной борьбе с представителями власти, желающими закрыть обитель и прервать в ней монашескую жизнь, то «священный текст» о любви к врагам приобретает конкретный смысл:

«Спустя месяцы, а порой и годы вчерашние враги возвращались к отцу Алипию уже не ради притеснения монастыря, а чтобы увидеть в Великом Наместнике <...> мудрого пастыря и духовника» (207).

В главе «Отец Иоанн», рассказывающей о судьбе проповедника, архимандрита Иоанна (Крестьянкина), на долю которого выпало множество испытаний (тюрьма, скитания по приходам, осуждение со стороны других священников), обнаруживаются косвенные отсылки к «священному тексту». Повествователь акцентирует внимание читателей на мыслях монаха о христианском отношении к врагам:

«Нам дана от Господа заповедь любви к людям, к нашим ближним. Но любят они нас или нет - нам об этом нечего беспокоиться! Надо лишь о том заботиться, чтобы нам их полюбить» (65).

Здесь проповедник лишь упоминает заповедь, хорошо знакомую адресатам поучения, избегая точного цитирования. При этом повествователь упоминает год и место произнесения 
проповеди: Михайловский собор Псково-Печерского монастыря, 1987 год.

В книге «Несвятые святые» изображается и так называемая «молчаливая проповедь», которая тесно связана с личностью иеромонаха Рафаила (Огородникова). В главах, посвященных жизнеописанию священнослужителя, он чаще всего показан вне богослужебного контекста: в бытовой обстановке, дома, во время путешествий. Снятие сакральности, акцент на житейских проблемах находит отражение и в названиях глав: «Приходской дом в Лосицах и его обитатели», «Как отец Рафаил пил чай» и т. д. Более того, автор акцентирует внимание на отсутствии у иеромонаха дара красноречия, что в определенной степени противоречит образу миссионера и проповедника:

«При этом, правду сказать, отец Рафаил даже проповеди не умел как следует составить. В лучшем случае: “Э-ээ... М-эээ... Братья, сестры, того... С праздником, православные!” (600).

На первый взгляд, ориентация на «священный текст» при описании «молчаливой проповеди» отца Рафаила полностью утрачивается. Кратко автор представляет и событийный ряд, чаще всего избегает пересказа бесед отца Рафаила со своими гостями, лишь в отдельных случаях включает в текст реплики и отдельные фрагменты диалога. Основное внимание повествователя концентрируется на итогах «молчаливой проповеди», после которой «все, с кем он пил чай, становились православными христианами»:

«Не знаю ни одного человека, кто, познакомившись с отцом

Рафаилом, после этого самым решительным образом не возродился бы к духовной жизни» (600).

Таким образом, книга архимандрита Тихона (Шевкунова) “"Несвятые святые” и другие рассказы» представляет собой развернутую проповедь, посвященную поиску и обретению пути к духовному спасению, встрече человека с Творцом.

Книга «Несвятые святые» содержит как проповеди самого повествователя, так и фрагменты поучений авторитетных служителей Церкви XX-XXI вв. Проповедь может обладать целостным и завершенным характером, ее содержание, как 
правило, связано с толкованием эпизода Священной истории, смысла праздника или знакового события из жизни монастыря (постриг). При этом наблюдается сочетание традиционных жанровых черт и элементов новаторства, к которым относится акцентирование внимания читателей на событиях повседневности, детализация, создание психологических и портретных характеристик, соединение тринитарной формулы и авторской оценки, эмоциональность, драматизм. Избранные реплики пастырей характеризуют их авторов как носителей глубокой веры, способствуют формированию образов пастыря-воина или пастыря-исповедника.

В произведении представлен особый феномен - «молчаливая проповедь», в которой отсутствует прямое обращение к «священному тексту», а основные жанровые элементы подвергаются редукции. На первый план в данной разновидности жанра выходит личности священнослужителя, его опыт проповеднической миссии - поучительная встреча изначально далекого от Бога и Церкви человека с Создателем и примирение с Ним.

\section{Примечания}

1 Тихон (Шевкунов), архимандрит. «Несвятые святые» и другие рассказы. М.: Изд-во Сретенского монастыря; Олма медиа групп, 2012. С. 636. Далее ссылки на это издание приводятся в тексте статьи с указанием страницы в круглых скобках.

2 Даль В. И. Толковый словарь живаго великорускаго языка [Электронный pecypc]. URL: http://slovardalja.net/word.php?wordid=34480 (10.01.19).

\section{Список литературы}

1. Агеева Г. А. Религиозная проповедь как специфический вид языковой коммуникации: На материале современных немецкоязычных проповедей: дис. ... канд. филол. наук. - Иркутск, 1998. - 183 с.

2. Амвросий (Ключарев), архиепископ. Искусство проповеди. - М.: Изд-во Сретенского монастыря, 2006. - 176 с.

3. Антоний (Вадковский), архиепископ. Из истории христианской проповеди. Очерки и исследования. - СПб., 1895. - 401 с.

4. Белкина Ю. А., Нестеров Д. А. Сравнительный анализ жанра проповеди различных христианских конфессий // Азимут научных исследований: педагогика и психология. - 2014. — № 4 (9). - С. 12-13.

5. Брага Дж. Как подготовить библейскую проповедь. - СПб.: Библия для всех, 1995. - 204 с. 
6. Бурега В. В. Проповедническая импровизация: теоретические подходы и практические советы [Электронный ресурс]. — URL: https://omiliya. org/article/propovednicheskaya-improvizatsiya-teoreticheskie-podkhodyi-prakticheskie-sovety.html (10.01.19).

7. Бурцев В. А. Дискурс русской православной проповеди: способы производства высказываний: дис. ... д-ра филол. наук. - Елец, 2012. - 447 с.

8. Волкова А. Г. Жанр византийской проповеди: богословие и поэтика (на материале проповеди Андрея Критского на Благовещение) // Вестник ВГУ. Серия: Филология. Журналистика. - 2014. — № 3. - С. 14-18.

9. Голубева Л. Д. Жанр проповеди в сборнике «"Несвятые святые” и другие рассказы» архимандрита Тихона Шевкунова // Художественный текст глазами молодых. Материалы международной научно-практической конференции. Ярославский государственный университет им. П. Г. Демидова. - Ярославль. - 2017. - С. 125-127.

10. Гроссу Н. С. Исторические типы церковной проповеди. - Киев, 1910. - $38 \mathrm{c}$.

11. Звездин Д. А. Православная проповедь как жанр церковно-религиозного стиля современного русского литературного языка: дис. ... канд. филол. наук. - Челябинск, 2012. - 201 с.

12. Истомина И. А. Современная православная проповедь: стилистическая и прагматическая специфика: дис. ... канд. филол. наук. - Екатеринбург, 2013. - $281 \mathrm{c}$.

13. Ицкович Т. В. О композиционно-тематическом развертывании церковной проповеди // Известия Уральского государственного университета. Серия 2. Гуманитарные науки. - 2006. - Вып. 11. - № 41. - С. 163-175.

14. Ицкович Т. В. Православная проповедь как тип текста: автореф. дис. ... канд. филол. наук. - Екатеринбург, 2007. - 24 с.

15. Крылова И. А. Современная православная проповедь в функционально-стилистическом аспекте: дис. ... канд. филол. наук. - СПб., 2005. - $227 \mathrm{c}$.

16. Пращерук Н. В. Современная духовная проза: традиции, смыслы, поэтика. - Екатеринбург, 2018. - 110 с.

17. Рогозин Д. М. Книга о монашестве как светский феномен // Социологический журнал. - 2012. - № 2. - С. 170-174.

18. Сибирева М. В. Проповедь митрополита Филарета (Дроздова) в русской литературе: проблемы жанра и стиля: дис. ... канд. филол. наук. 10.01.01. - M., 2008. - 240 c.

19. Скляров О. Н. «"Несвятые святые” и другие рассказы» арх. Тихона (Шевкунова): Повествователь. Адресат. Система персонажей. Нарративные стратегии // Журнал Narratorium. - 2017. - № 1 (10) [Электронный pecypc]. - URL: http://narratorium.rggu.ru/article.html?id=2637255 (05.11.2018).

20. Тихон (Шевкунов), архимандрит. «Несвятые святые» и другие рассказы. М.: Изд-во Сретенского монастыря; Олма медиа групп, 2012. - 640 с.

21. Футкарадзе Н. Д. Общие характеристики церковной проповеди как 
жанра религиозного дискурса // Вестник Ленинградского государственного университета им. А. С. Пушкина. - 2010. - № 1. - С. 141-146.

22. Шубина Т. А. Современная православная миссионерская проповедь: методика обучения жанру в высших духовных учебных заведениях: дис. ... канд. пед. наук. - М., 2008. - 259 с.

Информация об авторе: Леонов Иван Сергеевич - кандидат филологических наук, доцент ФГБОУ ВО «Государственный институт русского языка им. А. С. Пушкина».

Дата поступления в редакиию: 12.01.2019

Дата публикации: 29.03.2019

Ivan S. Leonov

(Moscow, Russian Federation)

mamif.lis@rambler.ru

\title{
The Genre of Preaching in the Poetics of the Book "“Unholy Saints" and Other Stories» by Archimandrite Tikhon (Shevkunov)
}

\begin{abstract}
The article is devoted to the peculiarities of the genre of preaching in the book of Archimandrite Tikhon (Shevkunov) "Unholy saints" and other stories». Both the narrator's sermons and the fragments of the sermons of authoritative priests of the 20th-21st centuries are exposed to the study which revealed that the sermons contain traditional genre features as well as some elements of innovation: a parallel appeal to the sacred text and the events of our time, specification, the creation of psychological characteristics, emotional tension, the combination of Trinitarian formulas and the author's assessment. In a number of chapters of the work there is a replacement of the text of the sermon with the large-scale predicatory content, a more detailed representation of episodes of everyday life, the transfer of events from the sacred to the household locus. The analysis of the phenomenon of a "silent sermon" reveals the reduction of its main genre elements, the absence of a direct reference to the sacred text, a particular attention to the personality of the preacher and the essence of his missionary vocation. Thus, the narrative is regarded as a comprehensive sermon about the meeting of man with his Creator.
\end{abstract}

Keywords: Orthodox fiction, Archimandrite Tikhon (Shevkunov), "Unholy saints" and other stories», sermon, sacred text, the Scripture, genre

\section{References}

1. Ageeva G. A. Religioznaya propoved' kak spetsificheskiy vid yazykovoy kommunikatsii: Na materiale sovremennykh nemetskoyazychnykh propovedey: dis. ... kand. filol. nauk [A Religious Sermon as a Specific Type of the Linguistic Communication: on the Material of Modern German-speaking Sermons. 
PhD. philol. sci. diss.]. Irkutsk, 1998. 183 p. (In Russ.)

2. Amvrosiy (Klyucharev), Archbishop. Iskusstvo propovedi [The Art of Preaching]. Moscow, Sretenskiy monastyr' Publ., 2006. 176 p. (In Russ.)

3. Antoniy (Vadkovskiy), Archbishop. Iz istorii khristianskoy propovedi. Ocherki $i$ issledovaniya [From the History of a Christian Sermon. Essays and Researches]. St. Petersburg, 1895. 401 p. (In Russ.)

4. Belkina Yu. A., Nesterov D. A. A Comparative Analysis of the Genre of Sermon of Various Christian Confessions. In: Azimut nauchnykh issledovaniy: pedagogika i psikhologiya ["ASR: Pedagogy and Psychology"], 2014, no. 4 (9), pp. 12-13. (In Russ.)

5. Braga G. Kak podgotovit' bibleyskuyu propoved' [How to Prepare a Biblical Sermon]. St. Petersburg, Bibliya dlya vsekh Publ., 1995. 204 p. (In Russ.)

6. Burega V. V. Propovednicheskaya improvizatsiya: teoreticheskie podkhody $i$ prakticheskie sovety [Evangelical Improvisation: Theoretical Approaches and Practical Suggestions]. Available at: https://omiliya.org/article/ propovednicheskaya-improvizatsiya-teoreticheskiepodkhody-i-prakticheskiesovety.html (accessed on January 10, 2019). (In Russ.)

7. Burtsev V. A. Diskurs russkoy pravoslavnoy propovedi: sposoby proizvodstva vyskazyvaniy: dis. ... d-ra filol. nauk [A Discourse of the Russian Orthodox Sermon: Methods of Production of Statements. PhD. philol. sci. diss.]. Yelets, 2012. 447 p. (In Russ.)

8. Volkova A. G. A Genre of the Byzantine Sermon: Theology and Poetics (on the Materials of the Sermon of Andrew of Crete on the Annunciation Day). In: Vestnik Voronezhskogo gosudarstvennogo universiteta. Seriya: Filologiya. Zhurnalistika [Proceedings of Voronezh State University. Series: Philology. Journalism], 2014, no. 3, pp. 14-18. (In Russ.)

9. Golubeva L. D. A Genre of Sermon in the Collection "Unholy Saints" and Other Stories» by Archimandrite Tikhon Shevkunov. In: Khudozhestvennyy tekst glazami molodykh. Materialy mezhdunarodnoy nauchno-prakticheskoy konferentsii [An Artistic Text Through the Eyes of Young People. Materials of the International Scientific-Practical Conference]. Yaroslavl, 2017, pp. 125-127. (In Russ.)

10. Grossu N. S. Istoricheskie tipy tserkovnoy propovedi [Historical Types of the Church Sermon]. Kiev, 1910. 38 p. (In Russ.)

11. Zvezdin D. A. Pravoslavnaya propoved' kak zhanr tserkovno-religioznogo stilya sovremennogo russkogo literaturnogo yazyka: dis. ... kand. filol. nauk [An Orthodox Sermon as a Genre of a Church-Religious Style of Modern Russian Literary Language. PhD. philol. sci. diss.]. Chelyabinsk, 2012. 201 p. (In Russ.)

12. Istomina I. A. Sovremennaya pravoslavnaya propoved': stilisticheskaya i pragmaticheskaya spetsifika: dis. ... kand. filol. nauk [A Modern Orthodox Sermon: Stylistic and Pragmatic Specifics. PhD. philol. sci. diss.]. Yekaterinburg, 2013. 281 p. (In Russ.)

13. Itskovich T. V. About a Compositional and Thematic Development of the Church Sermon. In: Izvestiya Ural'skogo gosudarstvennogo universiteta. Seriya 2. Gumanitarnye nauki [Izvestia. Ural Federal University Journal. 
Series 2. Humanities and Arts], 2006, issue 11, no. 41, pp. 163-175. (In Russ.)

14. Itskovich T. V. Pravoslavnaya propoved' kak tip teksta: avtoref. dis. ... kand. filol. nauk [An Orthodox Sermon as a Type of Text. PhD. philol. sci. diss. abstract]. Yekaterinburg, 2007. 24 p. (In Russ.)

15. Krylova I. A. Sovremennaya pravoslavnaya propoved' v funktsional'nostilisticheskom aspekte: dis. ... kand. filol. nauk [A Modern Orthodox Sermon in a Functional and Stylistic Aspect. PhD. philol. sci. diss.]. St. Petersburg, 2005. 227 p. (In Russ.)

16. Prashcheruk N. V. Sovremennaya dukhovnaya proza: traditsii, smysly, poetika [Modern Spiritual Prose: Traditions, Meanings, Poetics]. Yekaterinburg, 2018. 110 p. (In Russ.)

17. Rogozin D. M. The Book About Monasticism as a Secular Phenomenon. In: Sotsiologicheskiy zhurnal, 2012, no. 2, pp. 170-174. (In Russ.)

18. Sibireva M. V. Propoved' mitropolita Filareta (Drozdova) v russkoy literature: problemy zhanra i stilya: dis. ... kand. filol. nauk [A Sermon of Metropolitan Philaret (Drozdov) in Russian Literature: Problems of Genre and Style. PhD. philol. sci. diss.]. Moscow, 2008. 240 p. (In Russ.)

19. Sklyarov O. N "Unholy Saints" and Other Stories» of arch. Tikhon (Shevkunov): Narrator. Addressee. Character System. Narrative Strategies. In: Zhurnal Narratorium, 2017, no. 1 (10). Available at: http://narratorium. rggu.ru/article.html?id=2637255. (accessed on November 5, 2018). (In Russ.)

20. Tikhon (Shevkunov), Archimandrite. "Nesvyatye svyatye» $i$ drugie rasskazy ["Unholy Saints" and Other Stories]. Moscow, Sretenskiy monastyr' Publ., Olma media grupp Publ., 2012. 640 p. (In Russ.)

21. Futkaradze N. D. General Characteristics of Church Sermon as a Genre of a Religious Discourse. In: Vestnik Leningradskogo gosudarstvennogo universiteta im. A. S. Pushkina [Bulletin of Leningrad State University Named After A. S. Pushkin], 2010, no. 1, pp. 141-146. (In Russ.)

22. Shubina T. A. Sovremennaya pravoslavnaya missionerskaya propoved': metodika obucheniya zhanru $v$ vysshikh dukhovnykh uchebnykh zavedeniyakh: dis. ... kand. ped. nauk [A Modern Orthodox Missionary Sermon: Methods of Teaching of the Genre in Higher Spiritual Educational Institutions. PhD. pedagog. sci. diss.]. Moscow, 2008. 259 p. (In Russ.)

Information about the author: Leonov Ivan S. - PhD in Philology, Associate Professor of Pushkin State Russian Language Institute.

Received: January 12, 2019 Date of publication: March 29, 2019 